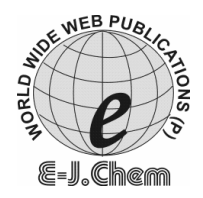

\title{
Kinetic Studies on the Oxidation of Some para and meta-Substituted Cinnamic Acids by Pyridinium Bromochromate in the Presence of Oxalic Acid (A Co-oxidation Study)
}

\author{
G. VANANGAMUDI* and S. SRINIVASAN \\ *P.G and Research Department of Chemistry, \\ Government Arts College, Chidambaram-608102, India. \\ Department of Chemistry, DDE, \\ Annamalai University, Annamalainagar-608 002, India. \\ gvsibi@yahoo.com
}

Received 29 October 2008; Revised 15 March 2009; Accepted 17 March 2009

\begin{abstract}
The kinetics of oxidation of cinnamic acids by pyridinium bromochromate $(\mathrm{PBC})$ in the presence of oxalic acid has been studied in acetic acid-water $(60: 40 \%)$ medium. The reaction shows unit order dependence each with respect to oxidant as well as oxalic acid [OX], the order with respect to $\left[\mathrm{H}^{+}\right]$and $[\mathrm{CA}]$ are fractional. The reaction is acid catalyzed and a low dielectric constant favours the reaction. Increase the ionic strength has no effect on the reaction rate. In the case of substituted cinnamic acids the order with respect to substrate vary depending upon the nature of the substituent present in the ring. In general, the electron withdrawing substituents retard the rate while the electron releasing substituents enhance the rate of reaction. From the kinetic data obtained the activation parameters have been computed and a suitable mechanism has been proposed.
\end{abstract}

Keywords: Kinetics, Oxidation of cinnamic acids, Activation parameters.

\section{Introduction}

In our earlier study, we have reported the kinetics of oxidation of cinnamic acids by pyridinium chlorochromate in the presence of oxalic acid has been studied in aqueous acetic acid medium ${ }^{1,2}$. The mechanistic path ways and nature of the transition state in the oxidation of single and multiple C-C bonds with chromium(VI) still remains controversial. The oxidation of cinnamic acid by various $\mathrm{Cr}(\mathrm{VI})$ reagents such as acid dichromate ${ }^{3,4,5}$, potassium dichromate in presence of picolinic acid $^{6}$ and quinolium dichromate ${ }^{7,8}$ have been reported. 
The substituents effects are very interesting because of possibility of the mechanism of the dual path, reported for stilbene bromination ${ }^{8}$, acid bromate oxidation ${ }^{9}$ of cinnamic acids and 1,10-phenanthroline catalysed $\mathrm{Cr}(\mathrm{VI})$ oxidation of some trans-cinnamic acids ${ }^{10,11}$ and hence, it was felt that it would be worthful to investigate the kinetics of oxidation of trans cinnamic acids by IDC by PBC and now we are here by presenting the results of the kinetics of oxidation of trans-cinnamic acids by PBC. Both the electron-releasing the electron withdrawing substituents facilitate the rate of oxidation. The oxidation of carbon-carbon multiple bonds by chromium(VI) reagents mainly leads to the formation of epoxides, glycols, aldehdyes, ketones and carboxylic acids ${ }^{12,13,14}$. Correlation with Hammett constants yields a ' $V$ ' shaped curve.

\section{Experimental}

Pyridinium bromochromate prepared as reported by Dhar et al ${ }^{15}$. Commercial samples of oxalic acid and substituted trans-cinnamic acids were collected (Merk) and used as such. All other chemicals were of AR grade. Acetic acid used as solvent was purified before use.

\section{Kinetics measurements}

The reactions were found under pseudo first order condition by maintaining always the substrate concentration in excess over that of PBC in presence of oxalic acid. Known volumes of substrate, water and acetic acid were mixed to bring the percentage of acetic acid to the desired volume and thermostated. The reaction was started by adding the oxidant to the mixture and aliquots were removed at definite time intervals and the unreacted $\mathrm{PBC}$ was estimated by standard iodometric titrations.

\section{Stoichiometry and product analysis}

The stoichiometry of the reaction was determined by carrying out several sets of experiments with varying amounts of $\mathrm{PBC}$ largely in excess over [CA]. The estimation of unreacted [PBC] showed that one mole of cinnamic acid react with one moles of PBC. The products were separated by column chromatography. An infrared spectrum exhibited a carbonyl band at $1705 \mathrm{~cm}^{-1}$ and certain other bands below $900 \mathrm{~cm}^{-1}$ characteristic of benzaldehyde. The IR spectrum of the other product sample have two sharp bands at 1680 and $1662 \mathrm{~cm}^{-1}$ indicating the presence of two carbonyl groups. Bands at $3620 \mathrm{~cm}^{-1}$ (OH stretching), 1360 $\mathrm{cm}^{-1}$ (C-O stretching) and $1152 \mathrm{~cm}^{-1}$ (OH bending) are characteristic of glyoxalic acid

\section{Results and Discussion}

Under pseudo first order conditions, the first order dependence on chromium(VI) was provided the linear semilogarithmic plots of log titre versus time $(\mathrm{r}=0.998)$. The observed rate constant values $\left(k_{\text {obs }}\right)$ did not vary appreciably with changing $\mathrm{Cr}(\mathrm{VI})$ concentrations. The effect of cinnamic acids on the reactivity $40{ }^{\circ} \mathrm{C}$ is shown in Table 1 . A plot of $k_{\mathrm{obs}}^{-1}$ versus $[\mathrm{CA}]^{-1}$ gave straight line with a slope of $0.68(\mathrm{r}=0.9974 ; \mathrm{SD}=0.030)$. The same behaviour was observed in all substituted transcinnamic acids. The order dependence on acidity was $<1$. Although the reaction is greatly affected by increase in acid concentration the plot of $\log k_{\text {obs }}$ versus $\mathrm{H}_{0}$ gives slope 0.80 . The catalytic activity of oxalic acid is shown in Table 2. In enhances the conversion of the unsaturated acids permitivity (D) value are calculated approximately from the values for pure solvents.

The low dielectric constant of the medium favors the reactivity as shown in Table 2. A plot of $\log k_{\mathrm{obs}}$ versus $\mathrm{D}$ gave straight line $(\mathrm{r}=0.998)$. The effect of ionic strength on the reactivity proved to be almost negligible Table 3 . The insensitivity of rates on added acrylonitrile ruled out 
a free radical process. The reaction rate increases tremendously with the increase in the concentration of added $\mathrm{MnSO}_{4}$ (Table 3). In the rate determining step, $\mathrm{Cr}(\mathrm{VI})$ gets converted to $\mathrm{Cr}(\mathrm{IV})$. Further $\mathrm{Cr}(\mathrm{IV})$ oxidises $\mathrm{Mn}^{2+}$ to $\mathrm{Mn}^{3+}$. The trivalent facilitates the oxidation rate. This type of reaction has been already studied Singh and Ghosh ${ }^{16}$ in the oxidation by mandellic acid. This confirms the formation of tetravalent chromium in the slow-step. The reaction rate is found to decrease by the addition of aluminium sulphate to the reaction mixture Table 4. This is obviously due to formation of complex between $\mathrm{Al}^{3+}$ and oxalic $\operatorname{acid}^{17}$. This observation leads to the assumption, that the ternary complex involving oxalic acid is intermediate in this type of co-oxidation reaction.

The rate of oxidation of meta and para-substituted trans-cinnamic acid are studied at four different temperature viz., 25, 30, 35 and $40{ }^{\circ} \mathrm{C}$. The activation parameters are calculated using Eyring's plot and the values are given in Table 4.

Table 1. Effect of [CA], [PBC] and [OX].

\begin{tabular}{cccc}
\hline $\begin{array}{c}{[\mathrm{CA}] \times 10^{2}} \\
\mathrm{~mol} \mathrm{dm}\end{array}$ & $\begin{array}{c}{[\mathrm{PBC}] \times 10^{3}} \\
\mathrm{~mol} \mathrm{dm}^{-3}\end{array}$ & $\begin{array}{c}{[\mathrm{OX}] \times 10^{2}} \\
\mathrm{~mol} \mathrm{dm}^{-3}\end{array}$ & $\begin{array}{c}k_{o b s} \times 10^{4} \\
\mathrm{~s}^{-1}\end{array}$ \\
\hline 0.5 & - & - & 1.19 \\
1.0 & - & - & 1.88 \\
1.5 & - & - & 2.54 \\
2.0 & - & - & 3.13 \\
2.5 & - & - & 3.47 \\
- & 0.50 & - & 1.84 \\
- & 0.75 & - & 1.79 \\
- & 1.00 & - & 1.88 \\
- & 1.25 & - & 1.81 \\
- & 1.50 & - & 1.75 \\
- & & 0.50 & 0.98 \\
- & & 1.00 & 1.88 \\
- & & 1.50 & 3.12 \\
- & & 1.75 & 3.67 \\
- & & 2.00 & 4.25 \\
\hline
\end{tabular}

$\left[\mathrm{H}^{+}\right]=11 \times 10^{-2} \mathrm{~mol} \mathrm{dm}{ }^{-3} ;$ Temp $=303 \mathrm{~K} ; \mathrm{AcOH}-60 \%(\mathrm{v} / \mathrm{v}) \mathrm{CA}=$ Cinnamic acid OX $=$ Oxalic acid .

Table 2. Effect of perchloric acid $\left[\mathrm{H}^{+}\right]$and acetic acid.

\begin{tabular}{ccc}
\hline$[\mathrm{H}] \times 10^{2} \mathrm{~mol} \mathrm{dm}^{-3}$ & $\mathrm{AcOH}, \%$ & $k_{\text {obs }} \times 10^{4} \mathrm{~s}^{-1}$ \\
\hline 2.75 & 60 & 0.75 \\
5.50 & 60 & 1.01 \\
8.25 & 60 & 1.34 \\
11.00 & 60 & 1.88 \\
12.58 & 60 & 2.31 \\
- & 50 & 0.41 \\
- & 55 & 1.12 \\
- & 60 & 1.88 \\
- & 65 & 2.45 \\
- & 70 & 3.61 \\
\hline
\end{tabular}

$[C A]=1.0 \times 10^{-2} \mathrm{~mol} \mathrm{dm} \mathrm{m}^{-3} ;[\mathrm{PBC}]=1.50 \times 10^{-3} \mathrm{~mol} \mathrm{dm}^{-3} ;[\mathrm{OX}]=1.0 \times 10^{-2} \mathrm{~mol} \mathrm{dm}^{-3} ; \mathrm{Temp}=303 \mathrm{~K}$. 
Table 3. Effect of manganous sulphate and sodium perchlorate.

\begin{tabular}{ccc}
$\begin{array}{c}{\left[\mathrm{Mn}^{2}\right] \times 10} \\
\mathrm{~mol} \mathrm{dm}^{-3}\end{array}$ & $\begin{array}{c}{\left[\mathrm{NaClO}_{4}\right] \times 10} \\
\mathrm{~mol} \mathrm{dm}^{-3}\end{array}$ & $\begin{array}{c}k_{\text {obs }} \times 10^{4} \\
\mathrm{~s}^{-1}\end{array}$ \\
\hline 5.00 & - & 1.54 \\
6.25 & - & 2.12 \\
7.50 & - & 5.36 \\
8.75 & - & 9.15 \\
10.00 & - & 17.6 \\
- & 5.0 & 3.42 \\
- & 6.25 & 3.41 \\
- & 7.50 & 3.36 \\
- & 8.75 & 3.51 \\
- & 10.00 & 3.37 \\
{$\left[\mathrm{CA}^{+}\right]=1.0 \times 10^{-2} \mathrm{~mol} \mathrm{dm}^{-3} ;[\mathrm{PBC}]=1.00 \times 10^{-3} \mathrm{~mol} \mathrm{dm}^{-3} ;[\mathrm{OX}]=1.0 \times 10^{-2} \mathrm{~mol} \mathrm{dm}^{-3} ;$} \\
{$\left[\mathrm{H}^{+}\right]=11 \times 10^{-2} \mathrm{~mol} \mathrm{dm}^{-3} ; \mathrm{AcOH}=60 \%(\mathrm{v} / \mathrm{v}) ; \mathrm{Temp}^{2}=303 \mathrm{~K}$.}
\end{tabular}

Table 4. Effect of aluminium sulphate and temperature.

\begin{tabular}{ccc}
{$\left[\mathrm{Al}^{3}\right] \times 10^{3} \mathrm{~mol} \mathrm{dm}^{-3}$} & $\mathrm{Temp}^{\circ}{ }^{\circ} \mathrm{C}$ & $k_{\text {obs }} \times 10^{4} \mathrm{~s}^{-1}$ \\
\hline 5.00 & - & 3.89 \\
6.25 & - & 3.42 \\
7.50 & - & 2.99 \\
8.75 & - & 2.18 \\
10.00 & - & 1.98 \\
- & 25 & 0.76 \\
- & 30 & 1.88 \\
- & 35 & 2.05 \\
- & 40 & 4.28 \\
{$[\mathrm{CA}]=1.0 \times 10^{-2} \mathrm{~mol} \mathrm{dm}^{-3} ;[\mathrm{PBC}]=1.00 \times 10^{-3} \mathrm{~mol} \mathrm{dm}^{-3} ;[\mathrm{OX}]=1.0 \times 10^{-2} \mathrm{~mol} \mathrm{dm}^{-3} ;$} \\
{$\left[\mathrm{H}^{+}\right]=11 \times 10^{-2} \mathrm{~mol} \mathrm{dm}^{-3} ; \mathrm{AcOH}=60 \%(\mathrm{v} / \mathrm{v})$.}
\end{tabular}

\section{Mechanism and rate law}

The kinetic of oxidation of cinnamic acid by PBC in the presence of oxalic acid in acid medium is first order with respect to [oxidant] as well as [oxalic acid], but the order in $\left[\mathrm{H}^{+}\right]$and [cinnamic acid] are fractional. In the absence oxalic acid, the rate of oxidation is very slow. The above facts reveal that there is a combined effect of oxidant, oxalic acid and H. One may presume that the increased rate of $\mathrm{CA}$ in the presence of oxalic acid is catalytic. The evolution of $\mathrm{CO}_{2}$ confirms that the oxalic acid is one of the participants in the main reaction, in cooxidation process. Such a phenomenon of a ternary system was already established. The absence of primary salt effect shows that the slow-step in this reaction is only between neutral species. This increase in the rate of oxidation by the addition of $\mathrm{Mn}(\mathrm{II})$ may be due to catalytic effect ${ }^{18}$.

The addition of $\mathrm{Al}^{3+}$ does affect the oxidation rate due to the formation of complex between $\mathrm{Al}^{3+}$ ion and oxalic acid. The possibility of radical formation is also ruled out by the absence of induced polymerization in the rate-determining step. Based on these observations the reaction mechanism, Scheme 1 has been proposed. Scheme 1 involved the formation of cyclic complex $\mathrm{C}_{2}$ by the reaction between oxidant, oxalic acids and $\mathrm{H}$ which interaction with CA forms another complex $\left(\mathrm{C}_{3}\right)$. The complex $\left(\mathrm{C}_{3}\right)$ rearranges to form a cyclic chromium(IV) diester $\left(\mathrm{C}_{4}\right)$ in the slow step. 

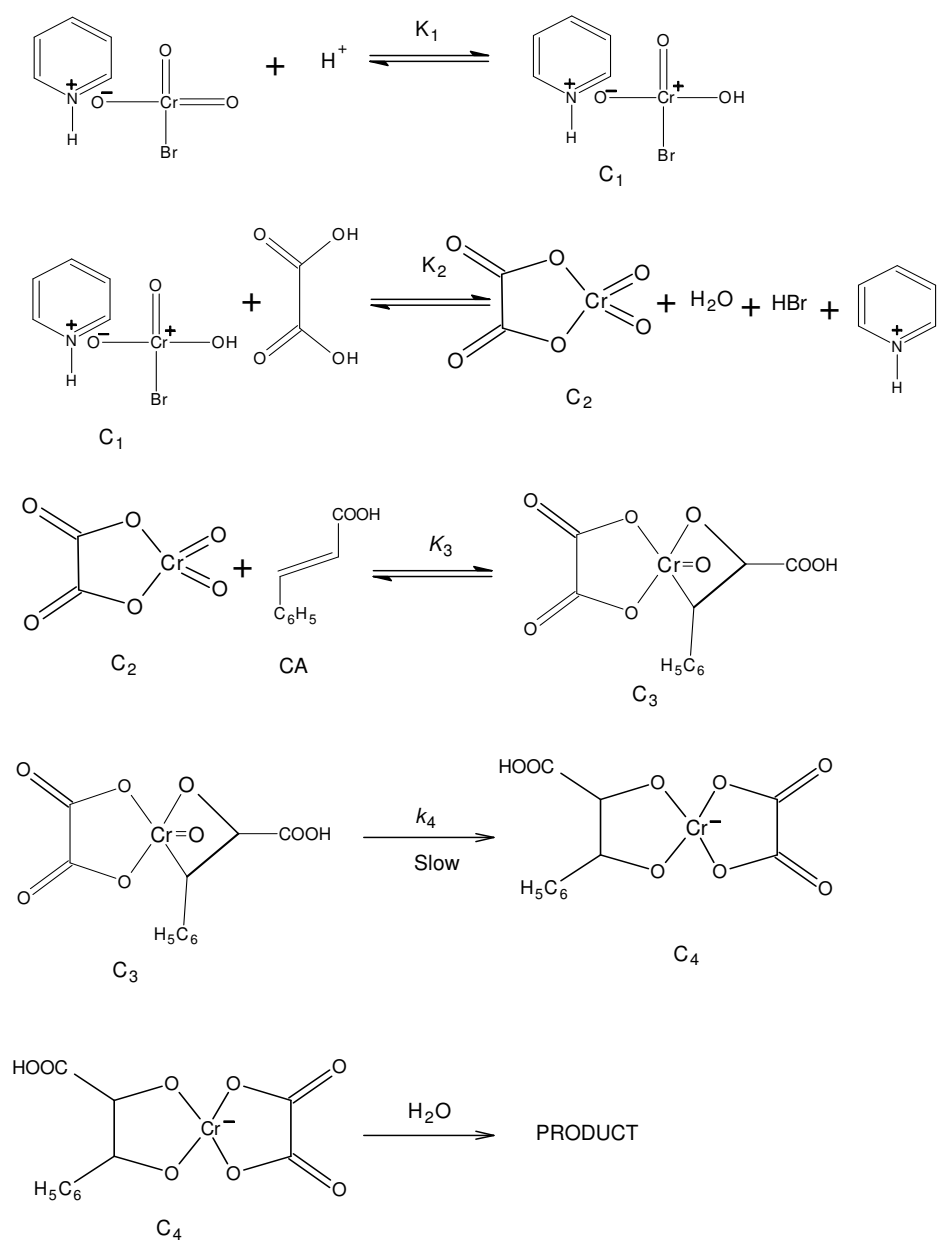

Scheme 1.

The complex $\left(\mathrm{C}_{3}\right)$ is formed by the following reaction (eq. 5) in which the double-bonds becomes $\eta_{2}$ ligand on chromium(VI) like $\mathrm{MnO}_{4}$ oxidation of $\mathrm{CA}^{19}$.

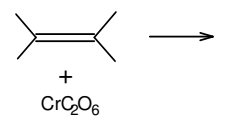

(1)

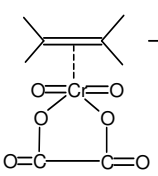

(2)

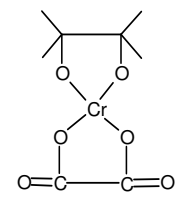

(5)
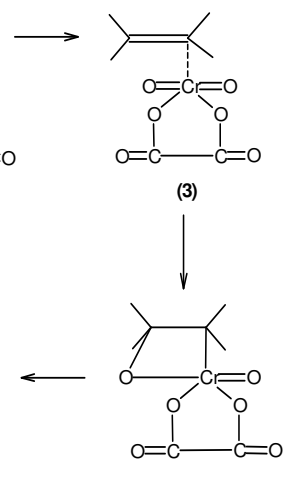

(4)

Scheme 2. 
When the chromium steps towards one end of the double bond (as in structure 3), acyclic organo-metallic compound is formed ${ }^{20,21}$. The first three steps involve the bond formation, whereas the last step required to cleavage of a $\mathrm{C}-\mathrm{Cr}$ bond. Consequently, it seems reasonable to consider the last step as the rate-limiting. From the above mechanism the rate law is derived as follows.

$$
\begin{aligned}
\text { Rate }=\mathrm{k}_{4} \mathrm{C}_{3} & =\frac{k_{4} K_{3}[\mathrm{CA}]\left[\mathrm{C}_{2}\right]}{\left\{1+K_{3}[\mathrm{CA}]\right\}} \\
& =\frac{k_{4} K_{3} K_{2}[\mathrm{CA}]\left[\mathrm{C}_{1}\right][\mathrm{OX}]}{\left\{1+K_{3}[\mathrm{CA}]\right\}} \\
& =\frac{k_{4} K_{3} K_{2} K_{1}[\mathrm{CA}]\left[\mathrm{H}^{+}\right][\mathrm{Cr}(\mathrm{VI})][\mathrm{OX}]}{\left\{1+K_{3}[\mathrm{CA}]\right\}\left\{1+K_{1}\left[\mathrm{H}^{+}\right]\right\}} \\
& =\frac{K_{1} K_{2} K_{3} k_{4}[\mathrm{CA}]\left[\mathrm{H}^{+}\right][\mathrm{OX}][\mathrm{Cr}(\mathrm{VI})]}{\left\{1+K_{3}[\mathrm{CA}] K_{1}\left[\mathrm{H}^{+}\right]+K_{3}[\mathrm{CA}]+K_{1}\left[\mathrm{H}^{+}\right]\right\}} \\
& =\frac{K_{1} K_{2} K_{3} k_{4}[\mathrm{CA}]\left[\mathrm{H}^{+}\right][\mathrm{OX}][\mathrm{Cr}(\mathrm{VI})]}{\left\{1+K_{1}\left[\mathrm{H}^{+}\right]+K_{3}[\mathrm{CA}]\right\}} \\
k_{\mathrm{obs}} & =\frac{K_{1} K_{2} K_{3} k_{4}[\mathrm{CA}]\left[\mathrm{H}^{+}\right][\mathrm{OX}]}{\left\{1+K_{1}\left[\mathrm{H}^{+}\right]+K_{3}[\mathrm{CA}]\right\}}
\end{aligned}
$$

Where, $\mathrm{CA}=$ Cinnamic acid; $\mathrm{OX}=$ Oxalic acid

\section{Effect of substituents on reaction rate}

The effect of substituents on the rate of oxidation has been studied with a number of ortho, meta and para-substituted cinnamic acid at four different temperatures. The respective rate consists and the thermodynamic parameters are given in Table 5 .

An analysis of the data has been made in respect of the linear free energy relationships. The Table 5 reveals that the entropy of activation is not constant throughout the series. In such cases, the variation in $\Delta S^{\#}$ should be linearly related ${ }^{21,22}$ to changes in $\Delta S^{\#}$ by equation.

$$
\Delta \mathrm{H}=\Delta \mathrm{H}_{0}^{\#}+\beta \Delta \mathrm{S}^{\#}
$$

The plot of enthalpy of activation $\left(\Delta \mathrm{H}^{\#}\right)$ against entropy of activation $\left(\Delta \mathrm{S}^{\#}\right)$ gave a straight line (Figure 1) with an excellent correlation coefficient $(\mathrm{r}=0.99)$. The isokinetic temperature obtained from slope is $343 \mathrm{~K}$. The linear relationship shows that all the substituted cinnamic acids follow a common mechanism.

Exner ${ }^{23,24}$ criticised the validity of such a linear correlation between $\Delta H^{\#}$ and $\Delta S^{\#}$ as their quantities are dependent on each other. When measurements at two different temperatures have been made the data can be analysed by the following equation.

where, $\mathrm{T}_{2}>\mathrm{T}_{1}$.

$$
\log \left(k_{2}\right)_{\mathrm{T}_{2}}=\mathrm{a}+\mathrm{b} \log \left(k_{2}\right)_{\mathrm{T}_{1}}
$$

Table 5 thermodymamic parameters for the oxidation of substituted cinnamic acids by $\mathrm{PBC}$ in the presence of oxalic acid calculated from plots of $\ln \left(k_{\mathrm{obs}} / \mathrm{T}\right)$ versus $1 / \mathrm{T}$ $(\mathrm{r}=0.998)$. 
Table 5. Thermodynamic parameters of substituted trans-cinnamic acid.

\begin{tabular}{|c|c|c|c|c|c|c|c|c|c|}
\hline \multirow{2}{*}{ S. No. } & \multirow{2}{*}{$\begin{array}{c}\text { Substituted } \\
\text { CA }\end{array}$} & \multicolumn{4}{|c|}{$k_{\text {obs. }} \times 10^{4} \mathrm{~s}^{-1}$} & \multirow{2}{*}{$\begin{array}{c}\Delta \mathrm{H}^{\#} \\
\mathrm{~kJ} \mathrm{~mol}^{-1}\end{array}$} & \multirow{2}{*}{$\begin{array}{c}\Delta \mathrm{S}^{\#} \\
\mathrm{~K}^{-1} \mathrm{~mol}^{-1}\end{array}$} & \multirow[b]{2}{*}{$\mathrm{r}$} & \multirow[b]{2}{*}{ SD } \\
\hline & & $25^{\circ} \mathrm{C}$ & $30^{\circ} \mathrm{C}$ & $35^{\circ} \mathrm{C}$ & $40^{\circ} \mathrm{C}$ & & & & \\
\hline 1 & $p$-OMe & 4.29 & 6.11 & 10.6 & 13.5 & 59.450 & -110.01 & 0.9899 & 0.08678 \\
\hline 2 & $p-\mathrm{Me}$ & 2.03 & 2.85 & 4.42 & 5.32 & 41.863 & -174.15 & 0.9826 & 0.08055 \\
\hline 3 & $m$-Me & 2.23 & 3.26 & 4.48 & 5.23 & 42.180 & -172.96 & 0.9852 & 0.0748 \\
\hline 4 & $\mathrm{H}$ & 0.76 & 1.88 & 2.05 & 4.28 & 78.904 & -57.258 & 0.9864 & 0.13418 \\
\hline 5 & $p-\mathrm{F}$ & 0.99 & 1.35 & 2.25 & 2.98 & 56.263 & -132.97 & 0.9927 & 0.06961 \\
\hline 6 & $p-\mathrm{Br}$ & 0.52 & 0.69 & 1.08 & 1.32 & 47.785 & -166.70 & 0.9897 & 0.07043 \\
\hline 7 & $p-\mathrm{Cl}$ & 0.62 & 0.82 & 1.02 & 1.28 & 34.862 & -208.45 & 0.9981 & 0.0217 \\
\hline 8 & $m-\mathrm{Cl}$ & 0.51 & 0.63 & 0.75 & 0.91 & 27.611 & -234.52 & 0.9996 & 0.00792 \\
\hline 9 & $m-\mathrm{NO}_{2}$ & 0.12 & 0.14 & 0.18 & 0.21 & 29.045 & -241.98 & 0.9990 & 0.01297 \\
\hline 10 & $p-\mathrm{NO}_{2}$ & 0.09 & 0.11 & 0.12 & 0.14 & 20.828 & -271.53 & 0.9903 & 0.02971 \\
\hline
\end{tabular}

$[P B C]=1.00 \times 10^{-3} \mathrm{~mol} \mathrm{dm}^{-3} ;\left[\mathrm{H}^{+}\right]=11 \times 10^{-2} \mathrm{~mol} \mathrm{dm}^{-3} ;[\mathrm{OX}]=1.00 \times 10^{-2} \mathrm{~mol} \mathrm{dm}^{-3} ; \mathrm{AcOH}=60 \%(\mathrm{v} / \mathrm{v})$.

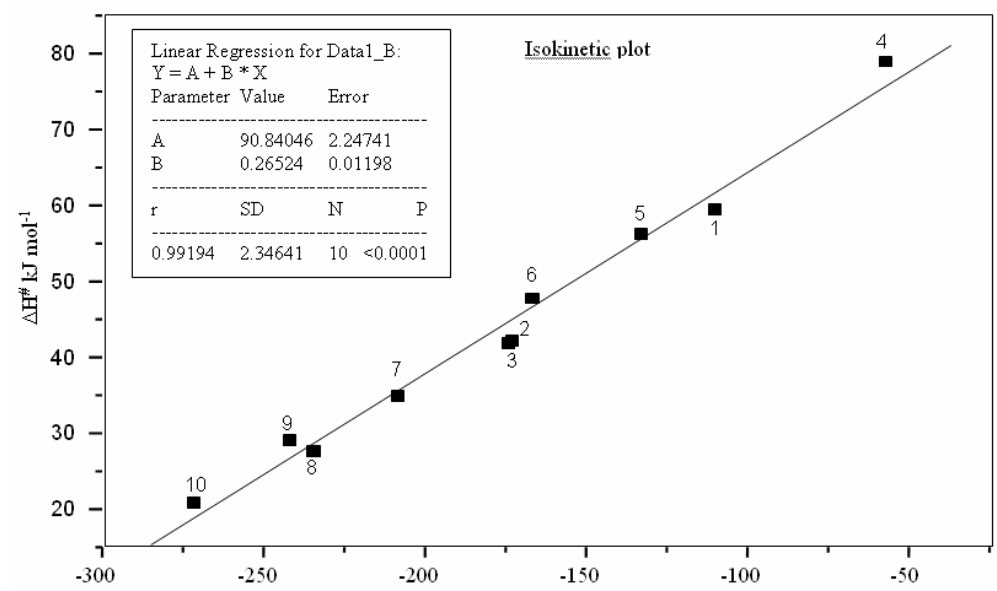

Figure 1. The plot of $\Delta \mathrm{H}^{\#}$ versus $\Delta \mathrm{S}^{\#}$.

The plot of $\log k_{\mathrm{obs}}\left(35^{\circ} \mathrm{C}\right)$ versus $\log k_{\mathrm{obs}}\left(25^{\circ} \mathrm{C}\right)$ gives straight line with $\mathrm{r}=0.998$. The good correlation indicates that all the investigated substituted compounds follow a common mechanism.

\section{Hammett equation}

The substituents when they are electron withdrawing retard the rate of reaction and when they are electron releasing, accelerate the rate of reaction. The $\rho$ values calculated from the plots of $\log k_{\mathrm{obs}}$ versus $\sigma$ at different temperatures were found to be negative Table 6 from the negative sign of the $\rho$ values it is inferred that an electron deficient transition state is formed during the oxidation.

Table 6. $\rho$ Values obtained from Hammett equation.

\begin{tabular}{cccc}
\hline Temperature ${ }^{\circ} \mathrm{C}$ & $\rho$ & $\mathrm{r}$ & $\mathrm{SD}$ \\
\hline 25 & -1.51 & 0.9840 & 0.1022 \\
30 & -1.59 & 0.9914 & 0.0787 \\
35 & -1.75 & 0.9947 & 0.0674 \\
40 & -1.78 & 0.9941 & 0.0724 \\
\hline
\end{tabular}




\section{Conclusion}

In all the investigated oxidation reactions in the absence and in the presence of oxalic acid with various oxidants, the reaction rate is retarded by electron-withdrawing groups and accelerated by electron-releasing groups. The $\rho$ values calculated from Hammett's plots of $\log k_{\text {obs }}$ against $\sigma$ at different temperatures indicate the formation of deficient transition state during oxidation in the presence of oxalic acid and the reactions with $\mathrm{Cr}(\mathrm{VI})$ oxidant the reaction rate is found to be higher than that in the absence of oxalic acid.

\section{Acknowledgement}

The authors are thankful to Prof.Dr.M.Subbaiyan, Formerly Professor and Head, Department of Analytical Chemistry, University of Madras.

\section{References}

1. Basheer Ahamed K A, Int J Chem Kinet., 2001, 33, 21.

2. Sabapathy Mohan R T, Gopalakrishnan M and Sekar M, Tetrahedron, 1994, 50, 37.

3. Vyas D N, Malkani R K, Mehta S B and Mehta S H, Chem Era., 1997,12, 33.

4. Meenakshisundaram S, Gopalakrishnan M, Nagarajan S, Sarathi N and Sumathi P, J Chem Res., 2005, 73.

5. Viroopakshappa J and Jagannadham V, Indian J Chem., 2004, 43(B), 374.

6. Vinothini R, Catalyzed $\mathrm{Cr}(\mathrm{VI})$ oxidation of cinnamic acids methionine, M Phil Thesis, Annamalai University, 2001.

7. Aruna K and Manikyamba P, Indian J Chem., 1995, 35A, 822.

8. Ruasse M F and Dubios J E, J Org Chem., 1973, 38, 493.

9. Sanjeeva Reddy C H and Sundaram E V, Tetrahedron, 1989, 45, 2109.

10. Meenakshisundaram S and Markandan R, Transition Metal Chemistry, 2004, 29, 308.

11. Meenakshisundaram S, Gopalakrishnan M, Nagarajan S and Sarathi N, Catl Commun., 2006, 7, 502.

12. Badanyan Sh O, Minasyan T T and Vardapetyan S K, Russian Chem Rev., 1987, 56, 740.

13. Nebaht D and Beytiye O, G U J Sci., 2006, 19, 9.

14. Bertmer M, Nieuwendaal R C, Barnes A B and Hayes S E, J Phys Chem., 2006, $110 \mathrm{~B}, 6270$

15. Dhar R K and Varadharajan R, Indian J Chem., 1991, 30A, 936.

16. Singh Dhakaray S P and Ghosh S, Indian J Chem., 1969, 7, 167.

17. Chandra S, Shukla S N and Chatterjee A C, Phy Chem., (Leipzing), 1968, 237, 137.

18. Subba Rao P V, et. al., Indian J Chem., 1991, 30A, 239.

19. Benito J F and Lee D G, J Org Chem., 1987, 52, 3239.

20. Vanangamudi G, Subbaiyan M, Gopalakrishnan M, Thirunarayanan G and Srinivasan S, Asian J Chem., 2007, 19, 1341.

21. Radhakrishnamurthi P S and Damoder Rao B V, Indian J Chem., 1981, 20A, 473.

22. Leffler J E, J Org Chem., 1995, 20, 1202.

23. Exner O, Coll Czech Chem Commun., 1964, 29, 1094.

24. Exner O, Nature, 1964,201, 488. 


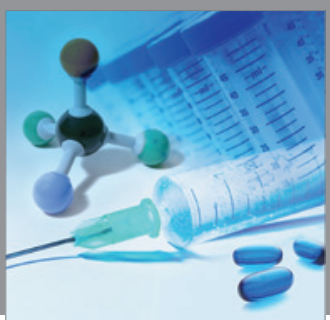

International Journal of

Medicinal Chemistry

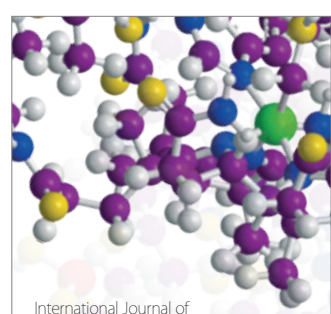

Carbohydrate Chemistry

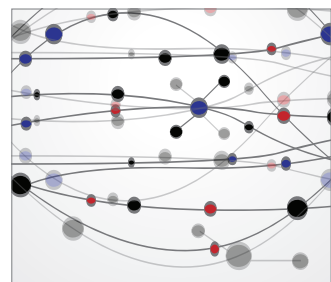

The Scientific World Journal
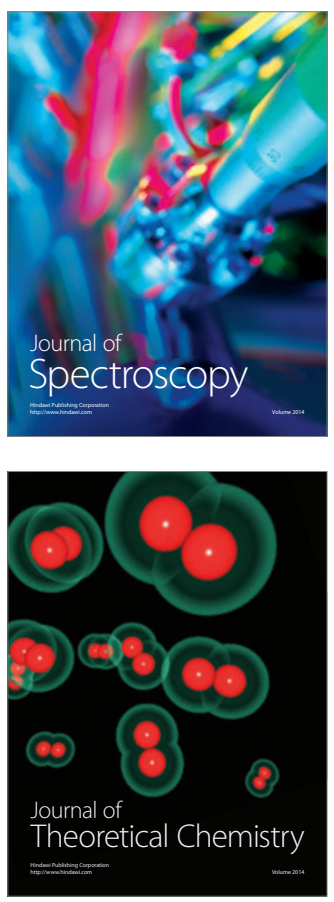
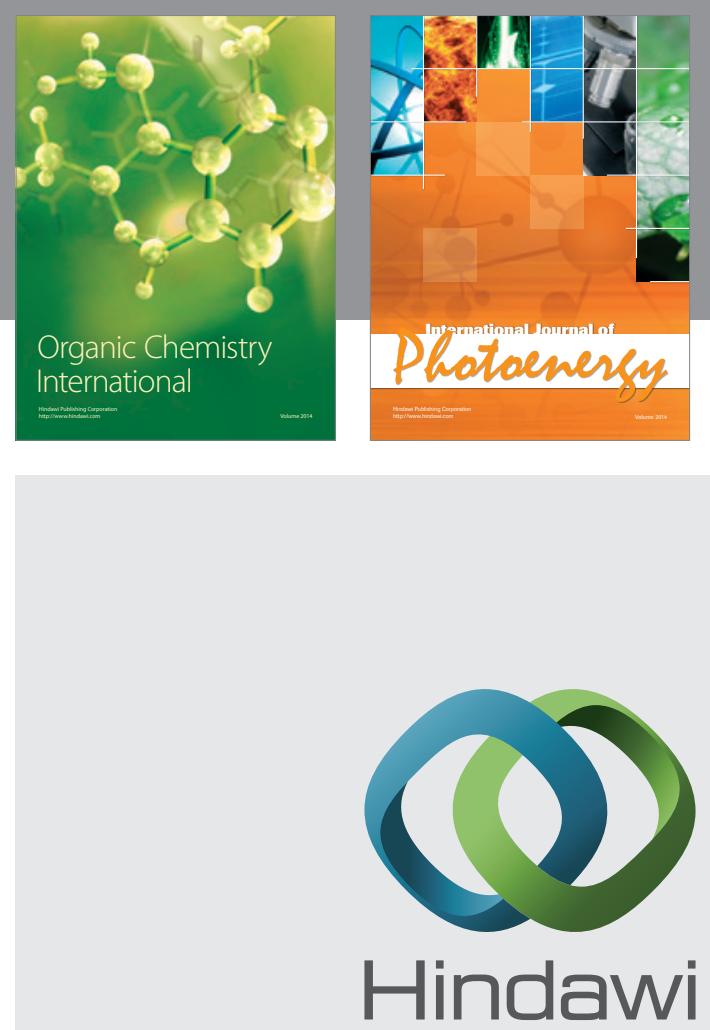

Submit your manuscripts at

http://www.hindawi.com
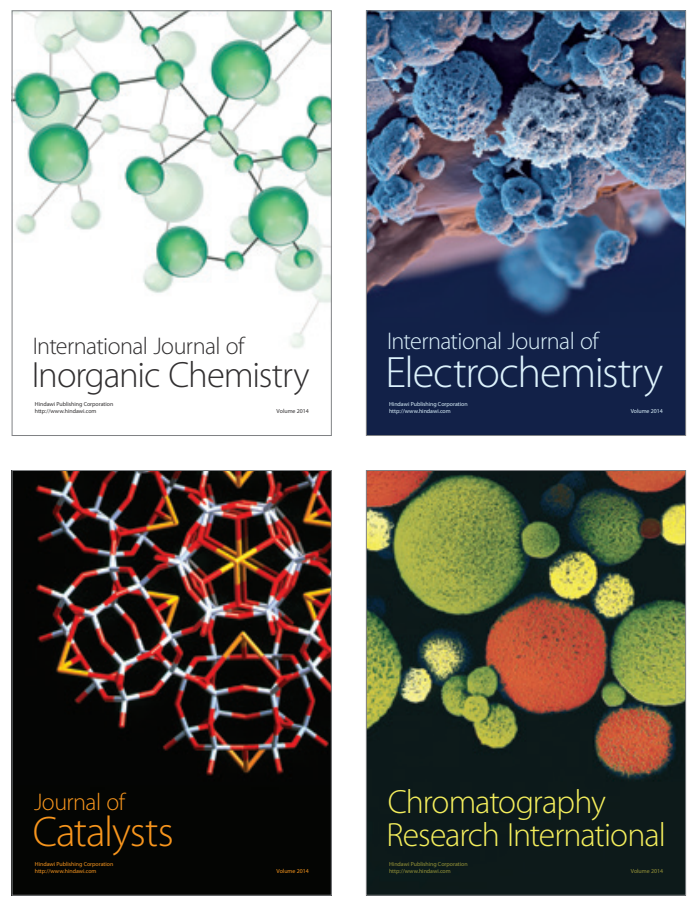
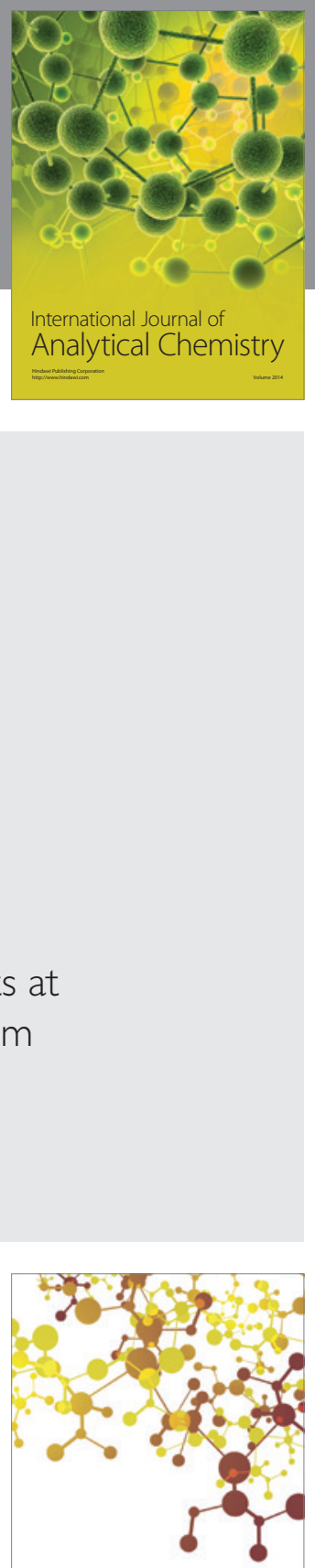

Journal of

Applied Chemistry
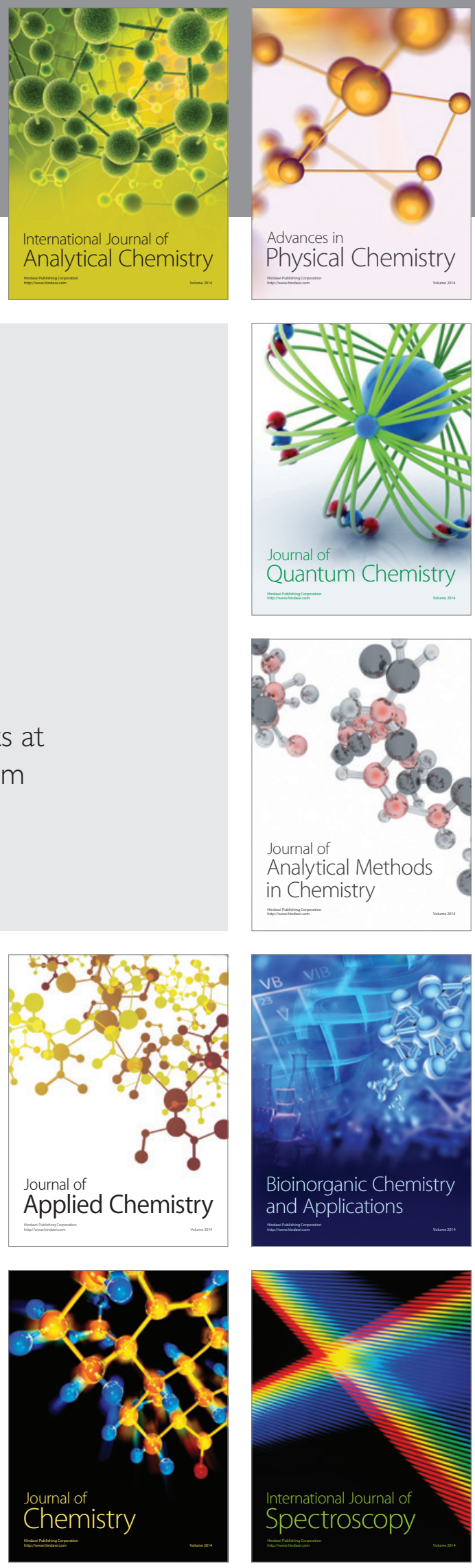